\title{
Study on Splitting Tensile Mechanical Properties of Carbon Fiber/Polymer Latex Powder Composite Modified Concrete
}

\author{
Xin Meng ${ }^{1, *}$, Erlei Bai ${ }^{1}$, Zhihang Wang ${ }^{1}$, Zhe Huang $^{1}$, Wei Xia ${ }^{1}$ \\ ${ }^{1}$ College of Aeronautics Engineering, Air Force Engineering University, Xi'an, Shaanxi, China
}

\begin{abstract}
The effects of carbon fiber and polymer latex powder on the split tensile mechanical properties of concrete in single and compound mixing conditions are studied. The results show that both carbon fiber or polymer latex powder can improve the split tensile strength and peak strain of concrete. When the carbon fiber content is $0.2 \%$, the split tensile mechanical properties of carbon fiber reinforced concrete (CFRC) are the best. When the amount is $8 \%$, the mechanical properties of polymer modified concrete (PMC) in split tension are the best. When the carbon fiber content is $0.3 \%$ and the polymer latex powder content is $0.8 \%$, the splitting tensile mechanical properties of the carbon fiber/polymer latex powder composite modified concrete (CFRPMC) specimens are the best, and are better than CFRC specimens and PMC specimens.
\end{abstract}

\section{Introduction}

With the development of science and technology in recent years, composite building materials such as fiber reinforced concrete and polymer modified concrete have become more and more widely used in the field of civil engineering [1,2]. Adding fibers to ordinary concrete can better improve its mechanical properties and increase its flexibility; adding polymers to ordinary concrete can better improve the transition zone between the aggregate and the cement stone and improve its deformation performance; adding polymer to fiber concrete can improve the dispersion of fiber in concrete, strengthen the bonding interface between fiber and matrix, and the polymer film formed by it can effectively improve the microstructure of the matrix [3-5].

In the current research on fiber/polymer composite modified concrete, the choice of fiber materials is very limited, mainly high-strength steel fibers and polymer fibers with a certain degree of flexibility [6,7]. There are few related studies on the selection of other types of fibers. In view of this, this paper selects carbon fiber and polymer latex powder to modify the concrete, and studies the influence of carbon fiber content on the split tensile mechanical properties of CFRC and the influence of the amount of polymer latex powder on the split tensile mechanical properties of PMC and CFRPMC.

\section{Experiment}

\subsection{Experiment material}

Cement, "Yaobai" brand 42.5 grade ordinary Portland cement, initial setting time $130 \mathrm{~min}$, fineness modulus
1.6. Water, Clean ordinary tap water with a $\mathrm{pH}$ value greater than 4 . Coarse aggregate, Limestone gravel, with a mud content of $0.2 \%$. Fine aggregate, Bahe sand, with a mud content of $1.5 \%$. Polymer latex powder, VINNAPAS ${ }^{\circledR} \quad 5044 \mathrm{~N}$ redispersible latex powder produced by Wacker in Germany. The latex powder is a highly flexible material composed of vinyl acetate ethylene copolymer (VAE), which can be dispersed into an emulsion in water. It has good compatibility with cement. Carbon fiber, PAN-based chopped carbon fiber with a diameter of $7 \mu \mathrm{m}$ and a length of $6 \mathrm{~mm}$. Water reducing agent, STHPC-03A FDN superplasticizer mother liquor. Defoamer, NOPCO NXZ type metal soap defoamer. Dispersant, hydroxyethyl cellulose dispersant. Film forming aid, DN-12 type film forming aid.

Water reducing agent is used to improve concrete construction performance and concrete strength. Defoaming agent is used to reduce bubbles generated in the mixing process. Dispersant is used to promote the dispersion of polymer latex powder and carbon fiber in cement paste. Film forming aids are used to enhance the plastic flow of polymer latex powder and promote coalescence to form a film.

\subsection{Experiment method}

The CFRPMC coordination ratio is shown in Table 1. Among them, PC stands for concrete specimens without carbon fiber and polymer latex powder, CFRC1, CFRC2, and $\mathrm{CFRC} 3$ stand for carbon fiber reinforced concrete specimens with a volume of $0.1 \%, 0.2 \%$, and $0.3 \%$ carbon fiber, respectively. PMC1, PMC2, PMC3 represent polymer modified concrete with $4 \%, 8 \%$, and $12 \%$ polymer latex powder by volume, respectively. CFRPMC1, CFRPMC2, and CFRPMC3 respectively

\footnotetext{
*Corresponding author: 1605153706@qq.com.
} 
represent the carbon fiber/polymer latex powder composite modified concrete with $0.3 \%$ carbon fiber volume content and $4 \%, 8 \%, 12 \%$ polymer latex powder volume content. The water-cement ratio in CFRPMC mix ratio is 0.49 , and the sand ratio is $34 \%$. The amount of dispersant (the percentage of the mass of the dispersant in the mass of cement) is $0.4 \%$. The amount of water-reducing agent (the mass of water-reducing agent accounts for the percentage of cement mass) is $1.2 \%$. The content of defoamer (the percentage of the mass of defoamer in the mass of cement) is $0.3 \%$. The dosage of the film-forming aid (the mass of the film-forming aid accounts for the percentage of the mass of the polymer latex powder) is $5 \%$.

Table 1. Mix ratio of CFRPMC

\begin{tabular}{|c|c|c|c|c|c|c|c|c|c|c|}
\hline \multirow{2}{*}{$\begin{array}{l}\text { Experiment } \\
\text { number }\end{array}$} & \multicolumn{10}{|c|}{ Raw material ratio $\left(\mathrm{kg} / \mathrm{m}^{3}\right)$} \\
\hline & $\begin{array}{l}\text { Carb- } \\
\text { on } \\
\text { fiber }\end{array}$ & $\begin{array}{c}\text { Polymer } \\
\text { latex } \\
\text { powder }\end{array}$ & $\begin{array}{c}\text { Cem- } \\
\text { ent }\end{array}$ & Water & $\begin{array}{c}\text { Coarse } \\
\text { aggre- } \\
\text { gate }\end{array}$ & $\begin{array}{c}\text { Fine } \\
\text { aggre- } \\
\text { gate }\end{array}$ & $\begin{array}{c}\text { Disper- } \\
\text { sant }\end{array}$ & $\begin{array}{c}\text { Water } \\
\text { reducing } \\
\text { agent }\end{array}$ & $\begin{array}{l}\text { Defoa- } \\
\text { mer }\end{array}$ & $\begin{array}{l}\text { Film } \\
\text { formin } \\
\text { g aids }\end{array}$ \\
\hline $\mathrm{PC}$ & 0 & 0 & 204 & 100 & 536 & 376 & 0.82 & 2.45 & 0.61 & 0 \\
\hline CFRC1 & 0.83 & 0 & 204 & 100 & 536 & 376 & 0.82 & 2.45 & 0.61 & 0 \\
\hline CFRC2 & 1.66 & 0 & 204 & 100 & 536 & 376 & 0.82 & 2.45 & 0.61 & 0 \\
\hline CFRC3 & 2.49 & 0 & 204 & 100 & 536 & 376 & 0.82 & 2.45 & 0.61 & 0 \\
\hline PMC1 & 0 & 8.17 & 204 & 100 & 536 & 376 & 0.82 & 2.45 & 0.61 & 0.41 \\
\hline PMC2 & 0 & 16.33 & 204 & 100 & 536 & 376 & 0.82 & 2.45 & 0.61 & 0.82 \\
\hline PMC3 & 0 & 24.50 & 204 & 100 & 536 & 376 & 0.82 & 2.45 & 0.61 & 1.23 \\
\hline CFRPMC1 & 2.49 & 16.33 & 204 & 100 & 536 & 376 & 0.82 & 2.45 & 0.61 & 0.82 \\
\hline CFRPMC2 & 2.49 & 8.17 & 204 & 100 & 536 & 376 & 0.82 & 2.45 & 0.61 & 0.41 \\
\hline CFRPMC3 & 2.49 & 24.50 & 204 & 100 & 536 & 376 & 0.82 & 2.45 & 0.61 & 1.23 \\
\hline
\end{tabular}

The preparation of CFRPMC specimens needs to go through six steps, namely weighing, fiber dispersion, polymer dispersion, stirring, forming and curing. The specific preparation process is as follows: (1) Use an electronic scale to weigh each raw material according to the mixing ratio. (2) Put the weighed water into the container for dispersing operation, use Tian D-8401W high-speed electric mixer to stir at low speed (120r/min), mix slowly and evenly with the dispersant while stirring, and wait until the solution is uniformly condensed. Stop stirring after glue. After 5 minutes, use a mixer to maintain a low-speed stirring state and slowly add the chopped carbon fiber to the dispersant solution, and continue stirring for about 10 minutes. After the fibers are uniformly dispersed into a monofilament state in the dispersion solution, add water reducing agent and filmforming aid Continue to stir at low speed for 60 seconds to prepare a well-dispersed carbon fiber dispersion for use. (3) The polymer latex powder is mixed with cement and manually stirred until the powder is evenly dispersed. (4) Pour the fine aggregate and half of the carbon fiber dispersion into the concrete mixer and mix for 60 seconds, add the coarse aggregate and mix for 60 seconds, add the dispersed powder to the mixer and mix for 60 seconds, add the remaining carbon fiber dispersion and mix for 60 seconds. Pour the remaining defoamer into the mixer and mix for 120 s, then pour the concrete out of the mixer and manually stir for 60s. (5) Put the stirred mixture into the mold, and tap it twice on the vibrating platform. In order to avoid the directional distribution of carbon fiber due to too long vibration time, each mechanical vibration is $30 \mathrm{~s}$, and the two mechanical vibrations are manually inserted. Pound for 30 seconds, and smooth the top of the test piece with a spatula after it is compacted. (6) Move the molded test piece into the room for curing. After 1 day, remove the mold and move it into a standard curing room for curing to 28 days. The size of the CFRPMC specimen is $100 \mathrm{~mm} \times 100 \mathrm{~mm} \times 100 \mathrm{~mm}$.

Use the HYY type electro-hydraulic servo material test system to perform split tensile test (as shown in Figure 1). Firstly, place the cured test piece with the cushion block, the cushion strip and the bracket as required, and then use the hydraulic tester to uniformly apply the load to the test piece at a loading speed of $0.05 \sim 0.08 \mathrm{MPa} / \mathrm{s}$ until the test piece is damaged, and record the damage Load and displacement.

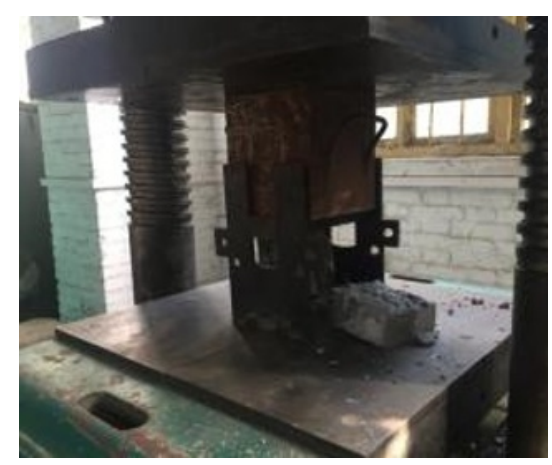

Fig. 1. Split tensile test

\section{Results and analysis}

\subsection{Effect of carbon fiber content on the mechanical properties of CFRC split tension}

The influence of carbon fiber content on CFRC split tensile mechanical properties is shown in Figure 2. It can be seen from the figure that as the content of carbon fiber increases, the split tensile strength and peak strain of CFRC both increase first and then decrease. When the carbon fiber content is $0.2 \%$, the split tensile strength and peak strain of CFRC are the largest, $3.42 \mathrm{MPa}$ and 
0.0011 , respectively, which increase by $40.16 \%$ and $57.14 \%$ respectively compared with the case without carbon fiber. When the content of carbon fiber is $0.3 \%$, the split tensile strength and peak strain of CFRC are reduced, but compared with the case without carbon fiber, they increase by $34.84 \%$ and $42.85 \%$, respectively. It can be seen that the addition of carbon fiber can improve the splitting mechanical properties of concrete specimens, and when the amount of carbon fiber is $0.2 \%$, the effect of improving the splitting mechanical properties of CFRC is the best.

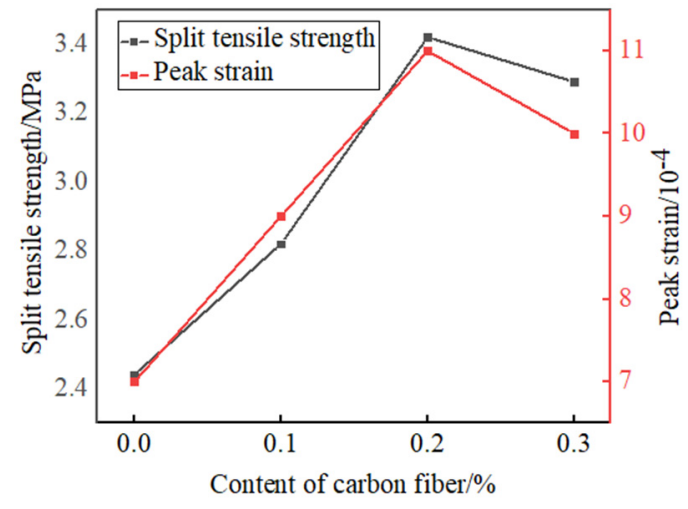

Fig. 2. The effect of carbon fiber content on CFRC split tensile strength and peak strain

\subsection{Effect of the content of polymer latex powder on the mechanical properties of PMC}

The influence of polymer latex powder content on the mechanical properties of PMC split tension is shown in Figure 3. It can be seen from the figure that with the continuous increase of the polymer latex powder content, the split tensile strength of PMC first increases and then decreases, and the peak strain continues to increase. When the polymer latex powder content is $8 \%$, the split tensile strength of PMC reaches the maximum, which is $3.18 \mathrm{MPa}$, which is an increase of $30.33 \%$ compared with the case without polymer latex powder. When the polymer latex powder content is $12 \%$, the peak strain of PMC reaches the maximum, which is 0.0009 . It can be seen that the addition of polymer latex powder can also improve the split tensile mechanical properties of concrete specimens.

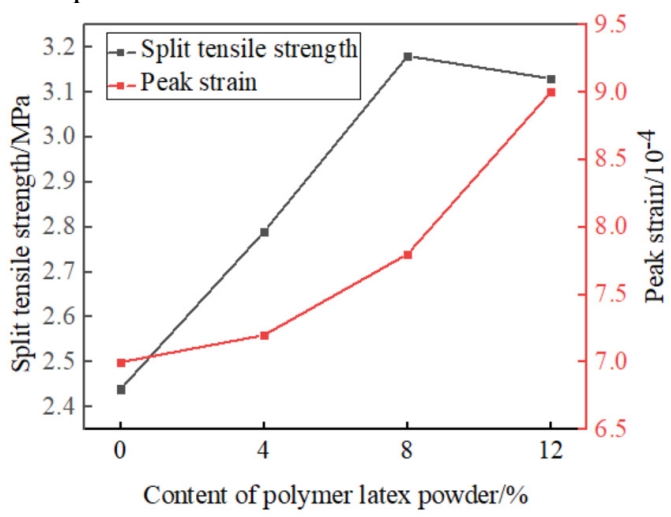

Fig. 3. The effect of polymer latex powder content on split tensile strength and peak strain of PMC

\subsection{Effect of the content of polymer latex powder on the mechanical properties of CFRPMC}

The influence law of polymer latex powder content on the split tensile mechanical properties of CFRPMC is shown in Figure 4. It can be seen from the figure that the split tensile strength and peak strain of CFRPMC both increase first and then decrease with the increase of polymer latex powder content. When the polymer latex powder content is $8 \%$, the split tensile strength and peak strain of CFRPMC are the largest, which are $4.4 \mathrm{MPa}$ and 0.0012 respectively. Compared with the concrete specimen without polymer latex powder and $0.3 \%$ carbon fiber content, the split tensile strength of CFRPMC increased by $33.74 \%$, and the peak strain increased by $30.00 \%$. It can be seen that adding polymer latex powder to CFRC can further improve its split tensile mechanical properties.

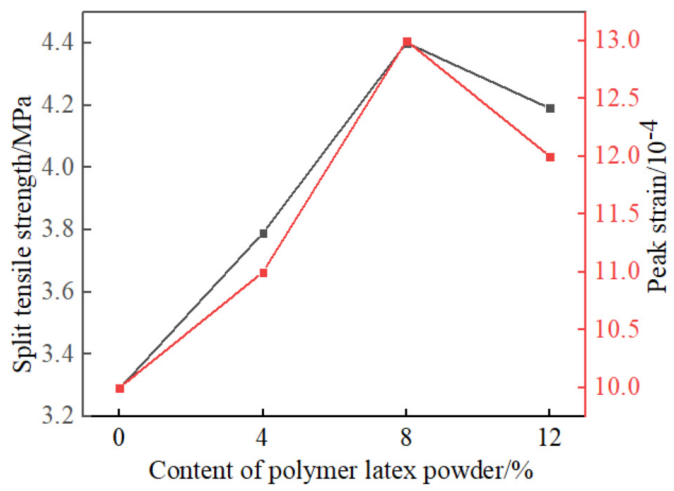

Fig. 4. The effect of polymer latex powder content on the split tensile strength and peak strain of CFRPMC

\subsection{Mechanism analysis}

When the two modifiers of carbon fiber and polymer latex powder are compounded, the modification effect on the split tensile mechanical properties of concrete is usually better than that of single modifier. This is because the emulsion formed by mixing polymer latex powder and water can assist the dispersion of carbon fibers. The incorporation of emulsion helps to reduce the thickness of the water-cement layer at the carbon fibercement stone interface, reduce the water-cement ratio difference between the interface layer and the cement stone matrix, and enhance the adhesion to the fiber surface. This greatly improves the carbon fiber-cement stone interface properties, the carbon fiber and cement stone also form a continuous phase at the interface. This increases the thickness of the matrix that can transmit the sliding force at the contact surface with the carbon fiber, thereby increasing the bond strength between the carbon fiber and the matrix. The carbon fiber is not easily pulled out when the concrete is under load, so that the performance of carbon fiber can be exerted to a greater extent. Therefore, when the two modifiers are mixed reasonably, the effect of modifying the splitting tensile mechanical properties of concrete is obviously better than that of single mixing. 


\section{Conclusion}

Both carbon fiber and polymer latex powder can improve the split tensile mechanical properties of concrete. When the content of carbon fiber is $0.2 \%$, the split tensile strength and peak strain of the CFRC specimens are both the largest. When the polymer latex powder content is $8 \%$, the split tensile strength of the PMC specimen is the largest.

When the content of carbon fiber is $0.3 \%$ and the content of polymer latex powder is $0.8 \%$, the split tensile mechanical properties of CFRPMC specimens are the best, and are better than those of CFRC specimens and PMC specimens.

When carbon fiber is mixed with polymer latex powder, its modification effect on the split tensile mechanical properties of concrete is usually better than that of single-mixed carbon fiber and polymer latex powder.

\section{Acknowledgments}

The authors would like to thank the National Natural Science Foundation of China (under grant no. 51208507) for the financial support.

\section{References}

1. Cao Q, Sun W, Guo L. (2010) Polymer-modified concrete with improved flexural toughness and mechanism analysis. Journal of Wuhan University of Technology-Mater Sci Ed. 27(3):597-601.

2. Beeldens A, Gemert DV, Schorn H. (2005) From microstructure to macrostructure: an integrated model of structure formation in polymer-modified concrete. Materials and Structures. 38(280):601-607.

3. Sun Z, Xu Q. (2008) Micromechanical analysis of polyacrylamide-modified concrete for improving strengths. Materials Science and Engineering: A. 490(1-2):181-192.

4. Bărbuţă M, Harja M, Baran I. (2010) Comparison of Mechanical Properties for Polymer Concrete with Different Types of Filler. JOURNAL OF MATERIALS IN CIVIL ENGINEERING. 22:696701.

5. Cao Q, Sun W, Guo L. (2012) Polymer-modified concrete with improved flexural toughness and mechanism analysis. Journal of Wuhan University of Technology-Mater Sci Ed. 27(3):597-601.

6. Wang ZhiHang, Xu JinYu, Bai ErLei. (2020) Dielectric Model of Carbon Nanofiber Reinforced Concrete. Materials. 13(21).

7. Wang Z, Xu J, Meng X. (2021) Effect of Ultraviolet Aging on the Bonding and Tensile Properties of Polymer-Cement Composite. JOURNAL OF RENEWABLE MATERIALS. 9(6):1157-116. 